\title{
Effect of prolonged intake of iron enriched diet on testicular functions of experimental rats
}

\author{
Mohamed M. El-Seweidy*, Mervat E. Asker, Sousou I. Ali, Hebatallah H. Atteia
}

Biochemistry Department, Faculty of Pharmacy, Zagazig University; *Corresponding Author: mmelseweidy@yahoo.com

Received 28 December 2009; revised 8 January 2010; accepted 23 March 2010.

\begin{abstract}
Iron deficiency anemia represents a common nutritional problem which affects many societies allover the world and iron fortified diet has been suggested as one of possible tools to combat and solve such problem. Present study was designed to illustrate the effect of dietary iron intake on certain biochemical markers dealing with oxidative stress, inflammatory response and cellular alterations of testicular tissues. Adult male rats which were fed on biscuits fortified with iron $(0.3 \%$ ferrous sulfate) daily for 10 weeks (iron group) showed increased serum iron, ferritin, tumor necrosis factoralpha (TNF- $\alpha$ ), nitric oxide (NO) and decreased Testosterone level $(p<0.05)$. Testicular tissues content of Malondialdehyde (MDA), hydroxyproline (Hyp), iron showed significant increase ( $p<$ 0.05 ) and decreased glutathione (GSH) as compared to control group. Testicular tissues demonstrated massive iron distribution in sertoli interstial tissues and degeneration of germinal epithelial cells. Apparent reduction in number of sperms and spermatogenic cells were also observed. These symptoms may demonstrate that prolonged intake of Biscuit fortified with iron causes certain testicular damage through certain mechanism.
\end{abstract}

Keywords: Iron Overload; Oxidative Stress; Inflammatory Response of Rat Testis

\section{INTRODUCTION}

Iron is an essential element for many cellular activities like oxygen transport, electron transfer [1] and gene regulation. However, an increase in cellular iron content may be toxic due to generation of reactive oxygen species (ROS) that damage proteins, lipids and DNA [2,3].

Iron deficiency anemia represents a common nutri- tional problem affecting large sector of individuals allover the world. Accordingly iron fortified diet was considered by some nutritionists as an effective tool and long term strategy to combat such kind of anemia.

This program was adopted and applied during last decades in different countries using different bakeries and breads fortified with Iron. Objectors to these idea stated that the possibility of toxicity from excess iron absorption of fortified diet was too great and thus such a measure should not be sponsored.Ten years ago Egyptian ministry of education, through its distributed institutes had adopted iron fortification program for different sectors of students especially young ages. This was achieved through daily supplementation to students of iron fortified biscuits $(0.3 \% \mathrm{w} / \mathrm{w})$. Till now this program was not evaluated properly, taken in consideration that additive iron here is greatly high. Healthy individuals may however face iron storage state even with moderate fortification of diet with iron, inducing inturn many varieties of chronic diseases [4]. Continuous iron intake may contribute to generation of free radicals and oxidation of cell components, an example is hepatocellular damage [5].

Testicular functions like liver cells are particularly vulnerable to such kind of injury and mostly mediated by reactive oxygen species (ROS) in consequence to iron overload. Oxidative damage here can either affect sperm cells or influence spermatogenic process which could change sperm functions. ROS can also activate transcription factors as nuclear factor-kappa B (NF-kB) which upregulates the transcription of adhesion molecules, cytokines and Enzymes as collective factors, mostly contributing to inflammatory response [6]. Chronic iron overload (CIO) can enhance proliferation and increase TNF- $\alpha$. The latter can also induce nitric oxide (NO) production from the activated polmorphonuclear leukocytes in response to tissues inflammation $[7,8]$. NO is an inorganic reactive nitrogen species synthesized in liver by iNos located in hepatocytes, kupffer, endothelial cells [9]. It represents a hepatoprotective mechanism against 
CIO toxicity [10]. Decreased level of Testosterone in male suffering from idiopathic hemochromatosis was reported before [11]. Androgenic deficiency as mentionned there not only produced by pituitary failure but also by testicular dysfunction due to hemosiderin deposition in testes. Oxidative stress may suppress also steroidogenesis. This is through substantial decrease in mRNA of steroid Acute regulatory protein (Star) as well as activities of testicular $\Delta^{5}-3 \beta$ and $17-\beta$ hydroxysteroid dehydrogenases [12]. Therefore present study aimed mainly to illustrate the effect of prolonged intake of iron enriched biscuits on oxidative stress, inflammation, testicular injuries and its degree in experimental rats. This may add great focus on such program having higher fortification degree with iron.

\section{MATERIALS AND METHODS}

A total of 30 wistar male albino rats $(180 \pm 20 \mathrm{~g}, 3$ months old) were supplied by the Egyptian Organization for Biological Products and Vaccines (Helwan farm, Cairo). Rats were housed in stainless steel rodent cages and kept under environmentally controlled conditions and allowed one week for acclimatization at room temperature with a $12 \mathrm{~h}$ dark/light cycle before starting the experimental work. During such time animals received normal rat chow (El-Nasr Pharmaceuticals Chemicals, Egypt), and allowed free access of drinking water.

\section{WORK DESIGN}

The rats were then divided into 2 groups, first one received in addition to normal chow, iron enriched biscuits ( $0.3 \%$ ferrous sulphate $\mathrm{w} / \mathrm{w})$ [13] daily for ten weeks (Fe group). Second group received iron free biscuits and served as control. This protocol was approved by the animal care and use committee of the Biochemistry Department, Faculty of Pharmacy, Zagazig University. Both groups, approximately consumed equal quantities of biscuits, its main components were: wheat flour, eggs, Butter, cane sugar and vanillin as flavor. Ten weeks after feeding, rats were fasted overnight and blood was collected via retro-orbital bleeding. Serum was prepared, and aliquots were stored at $-20^{\circ} \mathrm{C}$ for later determinations of: iron, ferritin, TNF- $\alpha$, testosterone and nitric oxide (NO).

Rats were killed by dissection. Testicular tissues were removed, rinsed with cold normal saline, divided into parts and dried with filter paper. First part was quickly frozen in liquid nitrogen $\left(-170^{\circ} \mathrm{C}\right)$ then stored at $-20^{\circ} \mathrm{C}$ for determination of biochemical parameters: malondialdehyde (MDA), Glutathione (GSH) Hydroxyproline
(Hyp) and iron contents.

The other part was kept in $10 \%$ formalin-saline at $4^{\circ} \mathrm{C}$ for 1 week, subsequently dehydrated with a series of ethanol solution from 75 to $100 \%$ before embedding in paraffin. Cross sections ( $5 \mu \mathrm{m}$ thick) were stained with hematoxylin and eosin ( $\mathrm{H} \& \mathrm{E}$ ) for routine light microscopy assessments, Perl's Prussian blue stain to localize deposited iron and Mallory trichrome stain to illustrate collagen fibers.

\section{ANALYTICAL PROCEDURES}

I: Serum iron was determined Colorimetrically by using The kits supplied by spinreact, (S.A., Spain) [14], NO as nitrite [15]. TNF- $\alpha$ was measured by using ELISA kits supplied by Biosource Int. (California, USA) [16]. Serum testosterone and ferritin were measured by electrochemiluminscence immunoassay "ECLIA" using commercial kits (Roche Diagnostics, USA) and Roche Elecsys 2010 immunoassay analyzers $[17,18]$.

II: Testicular tissues: MDA was determined spectrophotometrically by using thiobarbituric acid, TBA [19]. $0.5 \mathrm{G}$ tissue was homogenized in $5 \mathrm{ml}$ phosphate buffer $(\mathrm{PH}=7.2)$, centrifuged at $2000 \mathrm{~g}$ for $10 \mathrm{~min}$, supernatant fraction was used for MDA determination. GSH content was determined spectrophotometrically using Ellman's reagent according to modified method [20]. 0.1 G of tissues was homogenized in $1 \mathrm{ml}$ phosphate buffer $(\mathrm{PH}=$ 8 ) at $4^{\circ} \mathrm{C} .0 .5 \mathrm{ml}$ of homogenate was mixed with $0.5 \mathrm{ml}$ of 10 percent TCA in $5 \mathrm{mM}$ EDTA sodium, mixed well and centrifuged at $2000 \mathrm{~g}$ for $5 \mathrm{~min}$. Supernatant was used for determination of reduced GSH. Iron content was determined by flame atomic absorption Spectrophotometer [21]. About $0.1 \mathrm{G}$ tissues was digested in $2 \mathrm{ml}$ conc Nitric acid and $2 \mathrm{ml}$ perchloric acid at room temperature for 24 hours, the samples were filtered, diluted and absorption was measured at $248 \mathrm{~nm}$. Hyp was determined spectrophotometrically by Ehrlich reagent [22]. $0.1 \mathrm{G}$ tissues was pulverized ground, $500 \mathrm{ul}$ of $6 \mathrm{~N}$ $\mathrm{Hcl}$ were added and incubated overnight at $120 \mathrm{c} .5 \mathrm{ul}$ of acid hydrolysate were mixed with $5 \mathrm{ul}$ of citrate acetate buffer and $100 \mathrm{ul}$ chloramines $\mathrm{T}$ in ELISA plate and incubated for 20 minutes at room temperature before addition of Ehrlich solution.

\section{STATISTICAL ANALYSIS}

Analysis was carried out by using SPSS program for windows version 10 (SPSS, Chicago, USA). All results are presented as "Mean $\pm \mathrm{SD}$ ", student " $\mathrm{t}$ " test was used for the comparison between groups. Statistical significance was defined at $P<0.05$. 


\section{RESULTS}

Rats received biscuits enriched with iron (BEI) demonstrated significant increase in serum iron, ferritin, TNF- $\alpha$, NO and decreased testosterone level $(\mathrm{p}<0.05)$ (Table 1). Testicular contents of MDA, Hyp, and total iron demonstrated significant increase while GSH showed significant decrease $(\mathrm{p}<0.05)$ (Table 2).

Serum iron showed positive correlation with ferritin $r=0.8$, TNF- $\alpha r=0.57$ and negative one with testosterone $r=-0.72(p<0.05)$. Testicular iron content was positively correlated with MDA $r=0.948$, Hyp $r=0.978$ and negatively with GSH $r=-0.861(p<0.05)$.

The histopathological changes associated with $\mathrm{Fe}$ are illustrated in (Figures 1-6).

Table 1. Serum parameters of rats received iron fortified biscuits.

\begin{tabular}{ccc}
\hline Item & Control & BEI Group \\
\hline Iron $(\mathrm{mg} / \mathrm{dl})$ & $264.6 \pm 44.5$ & $518.45 \pm 90.2 \#$ \\
Ferritin $(\mathrm{ng} / \mathrm{ml})$ & $4.83 \pm 0.76$ & $10.58 \pm 90.2 \#$ \\
Testosterone $(\mathrm{ng} / \mathrm{dl})$ & $123.63 \pm 24.91$ & $43.92 \pm 9.3 \#$ \\
NO $(\mu \mathrm{mol} / \mathrm{l})$ & $34.23 \pm 4.69$ & $66.37 \pm 6.38 \#$ \\
TNF- $\alpha(\mathrm{pg} / \mathrm{ml})$ & $130.98 \pm 7$ & $213.6 \pm 4.33 \#$ \\
\hline
\end{tabular}

\# Significantly different from control at $P<0.05$.

Table 2. Testicular parameters of rats received iron fortified Biscuits.

\begin{tabular}{ccc}
\hline Item & Control & BEI \\
\hline MDA (nmol/g tissue) & $669.17 \pm 49.64$ & $1439 \pm 70.58 \#$ \\
GSH (nmol/g protein) & $38.09 \pm 1.93$ & $18.63 \pm 2.51 \#$ \\
Hyp $(\mu \mathrm{g} / \mathrm{g}$ tissue $)$ & $130.98 \pm 7$ & $213.6 \pm 4.33 \#$ \\
Iron $(\mu \mathrm{g} / \mathrm{gtissue})$ & $122.67 \pm 7.84$ & $265.17 \pm 11 \#$ \\
\hline
\end{tabular}

\# Significantly different from control at $\mathrm{P}<0.05$.

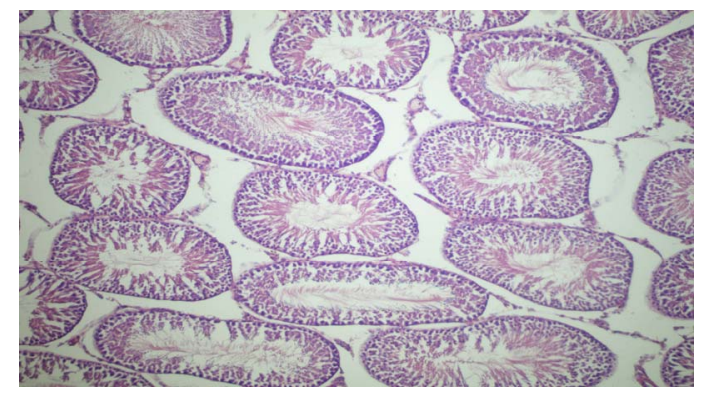

Figure 1. A photomicrograph of adult male albino rat testis (control group) showing seminiferous tubules (arrow) separated by interstitial tissue (double arrow) $(\mathrm{H} \& \mathrm{E} \times 100)$.

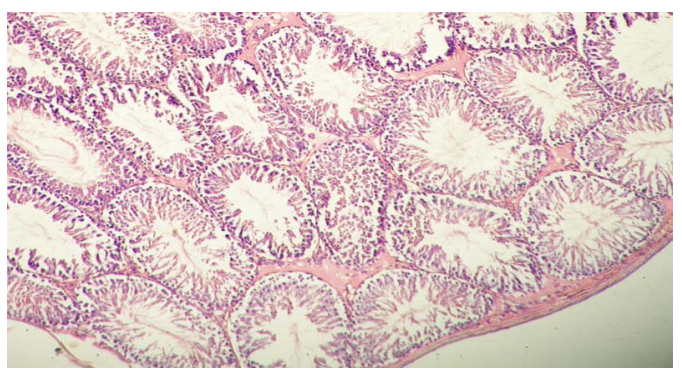

Figure 2. A photomicrograph of adult male albino rat testis of iron overload group showing adhesion of seminiferous tubules. Some tubules revealed disorganized germinal epithelium (arrow). Extensive area of exudates can be seen (double arrow) ( $\mathrm{H} \& \mathrm{E} \times$ 100).

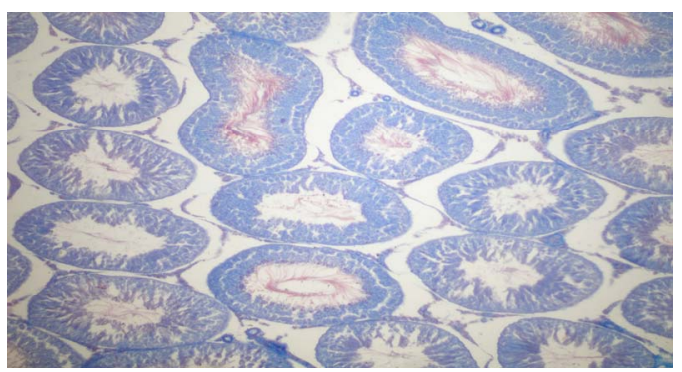

Figure 3. A photomicrograph of adult male albino rat testis (control group) showing distinctive boundary formed of collagen fibers (Mallory trichrome $\times$ 100).

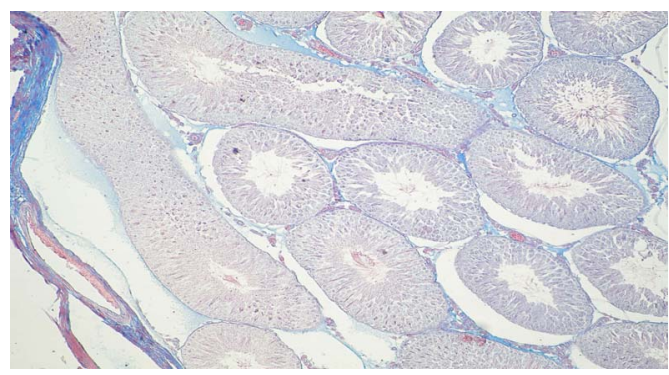

Figure 4. A photomicrograph of adult male albino rat testis (iron overload group) showing multiple collagen fibers (Mallory trichrome $\times 100$ ).

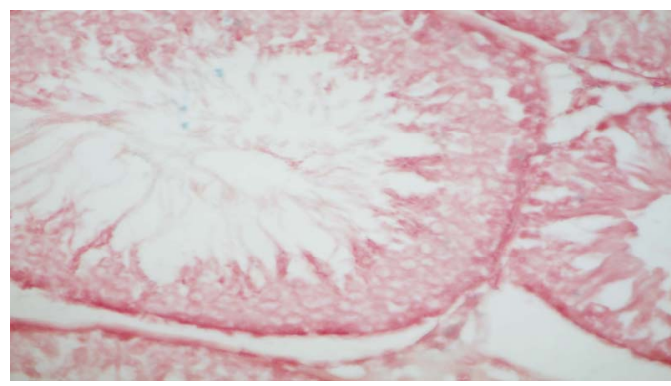

Figure 5. A photomicrograph of adult male albino rat testis (control group) showing negative Perl's Prussian blue stain (Perl's Prussian blue $\times 400$ ). 


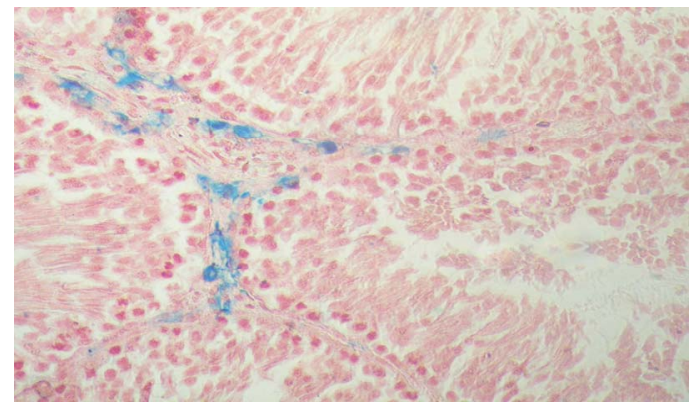

Figure 6. A photomicrograph of adult male albino rat testis (iron overload group) showing positive Perl's prussian blue stain (arrow) in interstitial tissue (Perl's Prussian blue $\times 400)$.

\section{DISCUSSION}

As mentioned above prolonged intake of iron enriched diet induced significant increase in serum iron and ferritin levels, in agreement with reported studies [23,24]. Previous report suggested that iron overload in rats can specifically activate target genes in the liver (i.e., L ferritin and procollagen) [25]. Similar study supported this suggestion, illustrated an increased expression of the heavy-chain isoform of ferritin mRNA in liver of iron overloaded rats [26]. Others suggested that the elevated non-transferrin bound iron (NTB iron); observed in ironoverloaded diseases may reflect two factors. First one,by increasing saturation degrees of transferrin it will reduce the number of plasma binding sites for NTB iron .This may increase the total plasma iron fraction in the NTB iron pool. The second factor may be liver damage [27].

Testicular iron content demonstrated significant increase (Table 2), in agreement with previous studies $[28,29]$ which considerd testicular tissues as secondary target for accumulated iron. This observation also implicates a regulation of iron transport which greatly differs from liver. It considers also that testis produce their own transferrin, and participates in iron shuttle system which fulfill the requirements of this metal for spermatogenesis [30].

Pro-oxidant effects of iron in testicular tissue are reasonable factor which mediates MDA increase and GSH decrease [31]. Other studies demonstrated GSH depletion, reduced activities of antioxidant enzymes like glutathione peroxidase, catalase, and superoxide dismutase [32]. In vitro study reported also similar findings [33].

Testicular content of Hyp demonstrated also significant increase in consistent with. Previous study [34] which may be due to increased activity of prolyl hydroxylase [35]. It was demonstrated before that iron overload induced moderate fibrosis in testes interstitium, interstitial macrophages, fibroblast and Leydig cells [36] meanwhile present study configurated similar findings (Fig- ure 4).

Last years many studies has been oriented to illustrate iron-induced oxidative stress, its effect on activation of the transcription factor nuclear factor-kappa B (NF-kB) [37]. NF-kB exists in an inactive state in the cytosol, usually as two subunits, p50and p65, complexed with inhibitory proteins (IkB). Degradation of inhibitory proteins can translocate NF-kB to the nucleus where it alters transcription of a number of genes involved in cell growth, differentiation, inflammation, and immune function. Such study suggested that NF-kB activation can be modulated by the redox status of the cell [38]. ROS can increase NF-kB activation while, antioxidant compounds including iron chelators can inhibit it [39].

NF-kB activation also plays a key role in the inflammatory process and upregulates the transcription of adhesion molecules, cytokines and enzymes involved in the inflammatory responses [40]. Present study demonstrated significant increase in TNF- $\alpha$ of iron group and, in agreement with recent study [13].

TNF- $\alpha$ may also activate NO production from the activated polymorphnuclear leukocytes in response to tissue inflammation [6]. The presence of nitrogen reactive species can explain the iron sequestration pattern which characterizes macrophages under inflammatory conditions.It may refer also to a complex relationship between iron and NO so that iron overload can also increase iron uptake by the liver Kupffer cells while No increase is mostly attributed to activated nitric oxide synthase [41].

NO expression is controlled also by the redox-sensitive transcription factor NF-KB [10], acting in iron overload state as hepatoprotective agent against iron toxicity.

This may be associated with increased NF-kB DNA binding to the iNOS gene promoter and higher expression and activity of iNOS mRNA [42].

Decreased serum testosterone in Fe group may be attributed to haemosiderin deposition in the pituitary gland [43] or cytotoxic effects of iron on the gonadotrophs [44].

Reported histopathological study indicated that excessive iron deposition caused degranulation of the adenohypophysiocytes and decreased hormone storage within such cells [45], additionally iron deposition in the anterior lobe of the pituitary gland can decrease its response to gonadotropin-releasing hormone [12]. Involvement of oxidative stress in the suppression of steroidogenesis was also reported before. This may be due to substantial reduction in the mRNA of steroid acute regulatory protein as well as activities of testicular $\Delta^{5}-3 \beta$ and $17-\beta$ hydroxysteroid dehydrogenases (HSD) through strong affinity of divalent heavy metal to the thiol groups of these proteins and enzymes [46].

Other reported studies indicated that TNF- $\alpha$ induced 
an early and transient increase in serum luteinizing hormone (LH), followed by a transient decrease in serum testosterone levels, while FSH demonstrated no change [47].

\section{CONCLUSIONS}

Taken together, the present study indicates that iron overload causes impairment in testicular activity and affects the androgenicity of male rats. This may be a reflection of iron deposition in testicular tissues, a matter which deserve great focus and attentions regarding such dietary program which have higher fortification degree with iron.

\section{ACKNOWLEDGEMENTS}

We acknowledge the financial support (Research grant) for the study presented from Biochemistry Department, Faculty of Pharmacy-Zagazig University.

\section{REFERENCES}

[1] Boldt, D.H. (1999) New perspectives on iron: An introduction. American Journal of the Medical Sciences, 318(4), 207-212.

[2] Houglum, K., Filip, M, Witztum, J.L. and Chojkier, M. (1990) Malondialdehyde and 4-hydroxynonenal protein adducts in plasma and liver of rats with iron overload. Journal of Clinical Investigation, 86(6), 1991-1998.

[3] Toyokunis, J. (2002) Iron and carcinogenesis: From fenton reaction to target genes. Redox Report, 7(4), 189-197.

[4] Swanson, C.A. (2003) Iron intake and regulation: Implications for iron deficiency and iron overload. Alcohol, 30(2), 99-102.

[5] Papanikolaou, G. and Pantapoulos, K. (2005) Iron metabolism and toxicity. Toxicology and Applied Pharmacology, 202(2), 199-211.

[6] Richard, A., Johnson, A.C. and Hanson, S. (2005) Parenteral iron compounds sensitize mice to injury-initiated TNF- $\alpha$ mRNA production and TNF- $\alpha$ release. American Journal of Physiology. Renal Physiology, 57(2), F290F297.

[7] Brown, K.E., Meleah, M., Keimberly, A. and Weydert, J. (2006) Chronic iron overload stimulates hepatocyte proliferation and cyclin D1 expression in rodent liver. Translational Research, 148(2), 55-62.

[8] Dunger, A., Cunningham, J.M., Delaney, C.A. and Lowe, E. (1990) Tumor necrosis factor- $\alpha$ and Interferone-y inibit insulin secretion and cause DNA damage in unweanled rat islets. Diabetes, 45(2), 183-189.

[9] Alderton, W., Cooper, C. and Knowles, R. (2001) Nitric oxide synthases: Structure, function and inhibition. Biochemical Journal, 357(Pt 3), 593-615.

[10] Cornejero, P., Fernandez, V., Vial, M. and Videla, L.A. (2007) Hepatoprotective role of NO in an experimental model of chronic iron overload. Nitric Oxide, 16(1), 143-149.
[11] Vogt, H.J., Weidenbach, T., Marqart, K.H. and Vogel, G. (1987) Idiopathic hemochromatosis in a 45 year old infertile man. Androlgia, 19(5), 532-538.

[12] Gupta, R.S., Gupta, E.S., Dhakal, B.K. and Thakur, A.R. (2004) Vitamin C and Vitamin E protect the rat testes from cadmium-induced reactive oxygen species. Mol cells, 17(1), 132-139.

[13] Elmegeed, G.A., Ahmed, H. and Hussein, J.S. (2005) Novel synthesized aminsteroidal hetrocycles intervention for inhibiting iron induced oxidative stress. European Journal of Medicinal Chemistry, 40(12), 1283-1294.

[14] Burits, C.A. and Ashwood, E.R. (1999) Methods for the determination of serum iron, iron binding capacity, and transferrin saturation. In: Burtis, C.A., Edward, R., Ashwood, M.D. and Tietz, N.W., Eds., Tietz Textbook of Clinical Chemistry, 3rd Edition, AACC, 1701-1703.

[15] Moshage, H., Kok, B., Huizenga, J.R., Jansen, P.L.M. (1995) Nitrite and nitrate determination in plasma: A critical evaluation. Clinical Chemistry, 41(6 Pt 1), 892896.

[16] Chen, W., Jin, W., Cook, M., Weiner, H.L. and Wahl, S.M. (1998) Oral delivery of group a streptococcal cell walls augments circulating TGF-beta and suppresses streptococcal cell wall arthritis. The Journal of Immunology, 161(11), 6297-6304.

[17] Wheeler, M.J. (1995) The determination of bio-available testosterone. Annals of Clinical Biochemistry, 32(Pt 4), 345-357.

[18] Lotz, J., Hafner, G. and Prellwitz, W. (1997) Reference study for ferritin assays. Kurzmitteilung Clinical Laboratory, 43(11), 993-994.

[19] Buege, J. and Aust, S. (1978) Microsomal lipid peroxidation. Methods Enzymology, 52, 302-306.

[20] Ahmed, A.E., Gamal, I.H., Loh, J. and Abdel-Rahman, S.Z. (1991) Studies on mechanism of haloacetonitrile induced gasyrointestinal toxicity, interaction of dibromoacetonitrile with glutathione as glutath ione-s-transferase in rats. Journal of Biochemical Toxicology, 6(2), 115-121.

[21] Basset, M.L., Halliday, J.W. and Powell, L.W. (1986) Value of hepatic measurement in early hemochromatosis and determination of the critical iron level associated with fibrosis. Hepatology, 6(1), 24-29.

[22] Fujita, M., Shannon, J.M., Morikawa, O., Gauldie, J., Hara, N. and Mason, R.J. (2003) Overexpression of tumor necrosis factor- $\alpha$ diminishes pulmonary fibrosis induced by bleomycin or transforming growth Factor- $\beta$. American Journal Respiratory Cell and Molecular Biology, 29(6), 669-676.

[23] Zhao, Y., Li, H., Gao, Z. and Xu, H. (2005) Effects of dietary baicalin supplementation on iron overload induced mouse liver oxidative injury. European Journal of Pharmacology, 509(2-3), 195-200.

[24] Silvana, M.L., Ribeiro, T., Sliva, M.E., Chianca, D.A., Paula, H.D., Cardoso, L.M., Colombari, E. and Pedrosa, L. (2003) Iron overload in hypercholesterolemic rats affects iron homeostasis and serum lipids but not blood pressure. Journal of Nutrition, 133(1), 15-20.

[25] Pietrangelo, A., Rocchi, E., Schiaffonati, L., Ventura, E. and Cairo, G. (1990) Liver gene expression during chronic dietary iron overload in rats. Hepatology, 11(5), 798-804. 
[26] Valerio, L.G.Jr. and Petersen, D.R. (2000) Characterization of hepatic iron overload following dietary administration of dicyclopentadienyl iron (ferrocene) to mice: Cellular, biochemical, and molecular aspects. Experimental and Molecular Pathology, 68(1), 1-12.

[27] Teresa, L., Brissot, P., Ma, W.-L. and Weisiger, R.A. (1986) Characterization of non-transferrin-bound iron clearance by rat liver. The Journal of Biological Chemistry, 261(23), 10909-10914.

[28] Lucesoli, F. and Fraga, C.G. (1999) Oxidative stress in testes of rats subjected to chronic iron intoxication and $\alpha$-tocopherol supplementation. Toxicology, 132(2-3), 179186.

[29] Galleano, M. and Puntarulo, S. (1997) Dietary a-tocopherol supplementatiom on antioxidant defenses after in vivo iron overload in rats. Toxicology, 124(1), 73-81

[30] Sylvester, S.R. and Griswold, M.D. (1993) Molecular biology of iron transport in the testis. In: De Krester, D., Ed., Molecular Biology of the Male Reproductive System, Academic Press, San Diego, 311-323.

[31] Harandi, A.A., Allameh, A. and O’Brien, P.J. (2005) In vivo effects of iron overload on toxicological parameters in isolated hepatocytes obtained from adult rats. FEBS Journal, 272(s1), 1-650.

[32] Jagetia, G.C., Reddy, T.K., Venkatesha, V.A. and Kedlaya, R. (2004) Influence of naringin on ferric iron induced oxidative damage in vitro. Clinica Chimica Acta, 347(12), 189-197.

[33] Alidoost, F., Gharagozloo, M., Bagherpour, B., Jafarian, A., Sajjadi, S.E., Hourfar, H. and Moayedi, B. (2006) Effects of silymarin on the proliferation and glutathione levels of peripheral blood mononuclear cells from beta-thalassemia major patients. International Immunopharmacology, 6(8), 1305-1310.

[34] Zhang, Y., Li, H., Zhao, Y. and Gao, Z. (2006) Dietary supplementation of baicalin and quercetin attenuates iron overload induced mouse liver injury. European Journal of Pharmacology, 535(1-3), 263-269.

[35] Poli, G. and Parola, M. (1997) Oxidative damage and fibrogenesis. Free Radical Biology and Medicine, 22(12), 287-305.

[36] Lucesoli, F., Caligiuri, M., Roberti, M.F., Perazzo, J.C. and Fraga, C.G. (1999) Dose-dependent increase of oxidative damage in the testes of rats subjected to acute iron overload. Archives of Biochemistry and Biophysics, 372(1), 37-43.

[37] Tsukamoto, H., Lin, M., Ohata, M., Giulivi, C., French,
S.W. and Brittenham G. (1999) Iron primes hepatic macrophages for NF-kB activation in alcoholic liver injury. American Journal of Physiology, 277(6 Pt 1), G1240G1250.

[38] Flohe', L., Brigelius-Flohe, R., Saliou, C., Traber, M.G. and Packer, L. (1997) Redox regulation of NF-kB activation. Free Radical Biology and Medicine, 22(6), 11151126.

[39] Li, S., Li, X. and Rozanski, G.J. (2003) Regulation of glutathione in cardiac myocytes. Journal of Molecular and Cellular Cardiology, 35(9), 1145-1152.

[40] Dunger, A., Cunningham, J.M., Delaney, C.A., Lowe, J.E., Green, M.H.L., Bone, A.J. and Green, I.C. (1996) Tumor necrosis factor- $\alpha$ and interferone- $\gamma$ inhibit insulin secretion and cause DNA damage in unweanted-rat islets. Diabetes, 45(2), 183-189.

[41] Galleano, M., Simontacchi, M. and Puntarulo, S. (2004) Nitric oxide and iron: Effect of iron overload on nitric oxide production in endotoxemia. Molecular Aspects of Medicine, 25(1-2), 141-154.

[42] Kleinert, H., Pautz, A., Linker, K. and Schwarz, P. (2004) Regulation of the expression of inducible nitric oxide synthase. European Journal of Pharmacology, 500(1-3), 255-266.

[43] Seracchioli, R., Porcu, F. and Colombi, C. (1994) Transfusion-dependent homozygous $\beta$-thalassemia major successful twin pregnancy following in-vitro fertilization and tubal embryo transfer. Human Reproduction, 9(10), 1964-1965.

[44] Sparacia, G., Iaia, A., Banco, A., D’Angelo, P. and Lagalla, R. (2000) Transfusional hemochromatosis: Quantitative relation of MR imaging pituitary signal intensity reduction to hypogonadotropic Hypogonadism. Radiology, 215(3), 818-823.

[45] Bergeron, C. and Kovacs, K. (1978) Pituitary siderosis: A histologic, immunocytologic and ultrastructural study. American Journal of Pathology, 93(2), 295-310.

[46] Wang, C., Tso, S. and Todd, D. (1989) Hypogonadotropic hypogonadism in severe beta-thalassemia: Effect of chelation and pulsatile gonadotropin-releasing hormone therapy. The Journal of Clinical Endocrinology and Metabolism, 68(3), 511-516.

[47] van der Poll, T., Romijn, J.A., Endert, E. and Sauerwein, H.P. (1993) Effects of tumor necrosis factor on the hypothalamic-pituitary-testicular axis in healthy men. $\mathrm{Me}$ tabolism, 42(3), 303-307. 